\title{
Occlusion in the digital era: a report on 3 cases
}

Smaranda Buduru ${ }^{1}$, Anca Mesaros² ${ }^{2}$ Daniel Talmaceanu³ ${ }^{3}$ Oana Baru², Raul Ghiurca ${ }^{3}$, Raluca Cosgarea ${ }^{1}$

1) Department of Prosthodontics, Iuliu Hatieganu university of Medicine and Pharmacy, Cluj-Napoca, Romania

2) Department of Propaedeutics and Dental Aesthetics, Iuliu Hatieganu university of Medicine and Pharmacy, Cluj-Napoca, Romania

3) Stomestet Dental Clinic, ClujNapoca, Romania

DOI: $10.15386 / \mathrm{mpr}-1524$

Manuscript received: 30.07 .2019

Received in revised form: 06.09.2019 Accepted: 04.11.2019

Address for correspondence:

ancames@yahoo.com

\begin{abstract}
In the following case studies we wish to discuss the necessity of making use of digital technology in the occlusion-oriented dental practice. In the three presented cases, patients underwent complex orthodontic, implant and prosthetic treatment, the aim being to re-establish the functionality of the dento-maxillary apparatus. The patients were evaluated clinically at the completion of the treatment. Subsequently, during the follow-ups (which varied between 2 and 4 years), clinical analysis using articulating paper was carried out and possible signs of relapse were specifically searched for. Occlusal clinical analysis was later on compared with the occlusion recorded using the TRIOS ${ }^{\circledR} 3$ intraoral scanner (3Shape) and the T-Scan ${ }^{\mathrm{TM}}$ Novus $^{\mathrm{TM}}$ device (TekScan). Clinical and digitally obtained scanner results were similar. The results yielded by the T-Scan ${ }^{\mathrm{TM}}$ Novus $^{\mathrm{TM}}$ device were different and they were also relevant for elucidating the cause of the symptomatology.
\end{abstract}

Keywords: occlusal analysis, articulating paper, intraoral scanner, TRIOS 3, T-Scan

\section{Introduction}

Digital technology is becoming increasingly popular in our profession. Computerized prosthetic restorations are no longer a scenario of the future or a pioneering enterprise; on the contrary, they have become current practice. Many doctors and dental technicians are relying more and more on $\mathrm{CAD} / \mathrm{CAM}$ technology in their daily practice [1]. The digital approach consists of taking digital impressions using intraoral or cast scanners, computerized design of the prosthetic works, and computerized milling or printing of the dental restorations. Intraoral scanners have a wider range of dental indications and applicability and have also improved their performance [2,3]. Thus, the latest generations of intraoral scanners do no longer require powder to be applied on the dental arches, and their speed and accuracy has increased. Moreover, the scanner head has become smaller, which facilitates its manipulation. Another quality is color scanning and, thus, the possibility of color determination [4]. Initial indications that referred to obtaining 1 to 4 prosthetic units have changed, allowing the design and completion of vast prosthetic works, implant-based restorations and even of a full denture $[5,6]$. As for computerized design, new scanners have virtual articulators that enable the creation of a virtual design as much adapted occlusally as possible. These virtual articulators can perform condylar programming through computerized methods such as axiography, facial scanning or digital analysis of condylar movements [7-11]. Other computerized occlusal analysis determines simultaneously the first occlusal contacts, their evolution in time, as well as the intensity of forces during all mandibular movements $[12,13]$.

The aim of these case studies is to clinically determine the differences between classical occlusal analysis using articulating paper, computerized (T-Scan) and intraoral scanner analysis (TRIOS 3).

\section{Case studies}

The patients in the cases presented here were clinically examined using Bausch articulating paper $(100 \mu \mathrm{m}$ and 40 $\mu \mathrm{m}$ thick) and the results were compared with those yielded by the TRIOS ${ }^{\circledR}$ 3 (3Shape) intraoral scanner and the T-Scan ${ }^{\mathrm{TM}}$ Novus $^{\mathrm{TM}}$ device (TekScan). 


\section{Case 1}

A male patient, 23 years old, came to our clinic complaining of generalized dental sensitivity to thermic and sweet stimuli. Upon clinical analysis, all lateral teeth and the palatal surfaces of the upper anterior teeth were found to be worn (Figure 1).

Further investigation led to the diagnosis of Angle Class III malocclusion, dento-maxillary disharmony with bimaxillary crowding, mandibular laterognathism and right posterior crossbite with a tendency to open bite. This situation had generated severe occlusal pathology through the lack of functional relations both in centric relation (CR)/maximum intercuspation (MI), as well as in functional anterior and lateral guidances. The decision was to treat orthodontically by aligning and levelling, reducing the crossbite and the intrusion of the lateral teeth in order to obtain prosthetic space. A prosthetic treatment using inlays, onlays, posterior table tops and upper anterior palatal veneers was carried out at the end of the orthodontic treatment in order to re-establish functional occlusal parameters. At the 4-year follow-up, the patient complained about a slight cold sensitivity on tooth 2.7 (Figure 2).
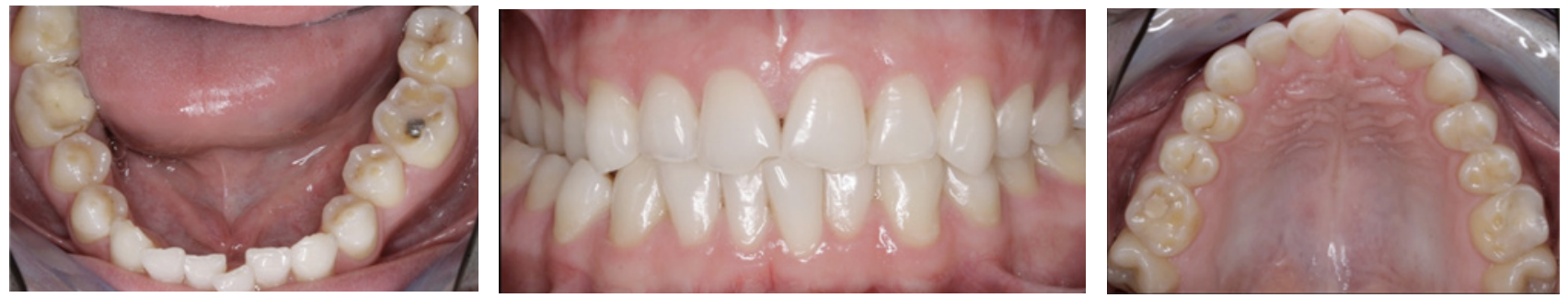

Figure 1. Initial situation: worn teeth.

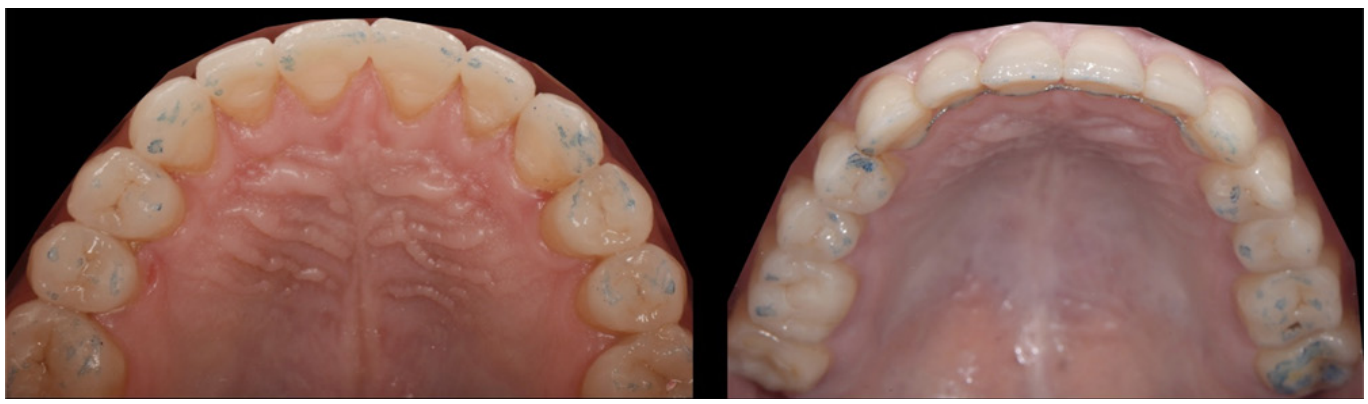

Figure 2. Clinical analysis at the end of the treatment and after 4 years.
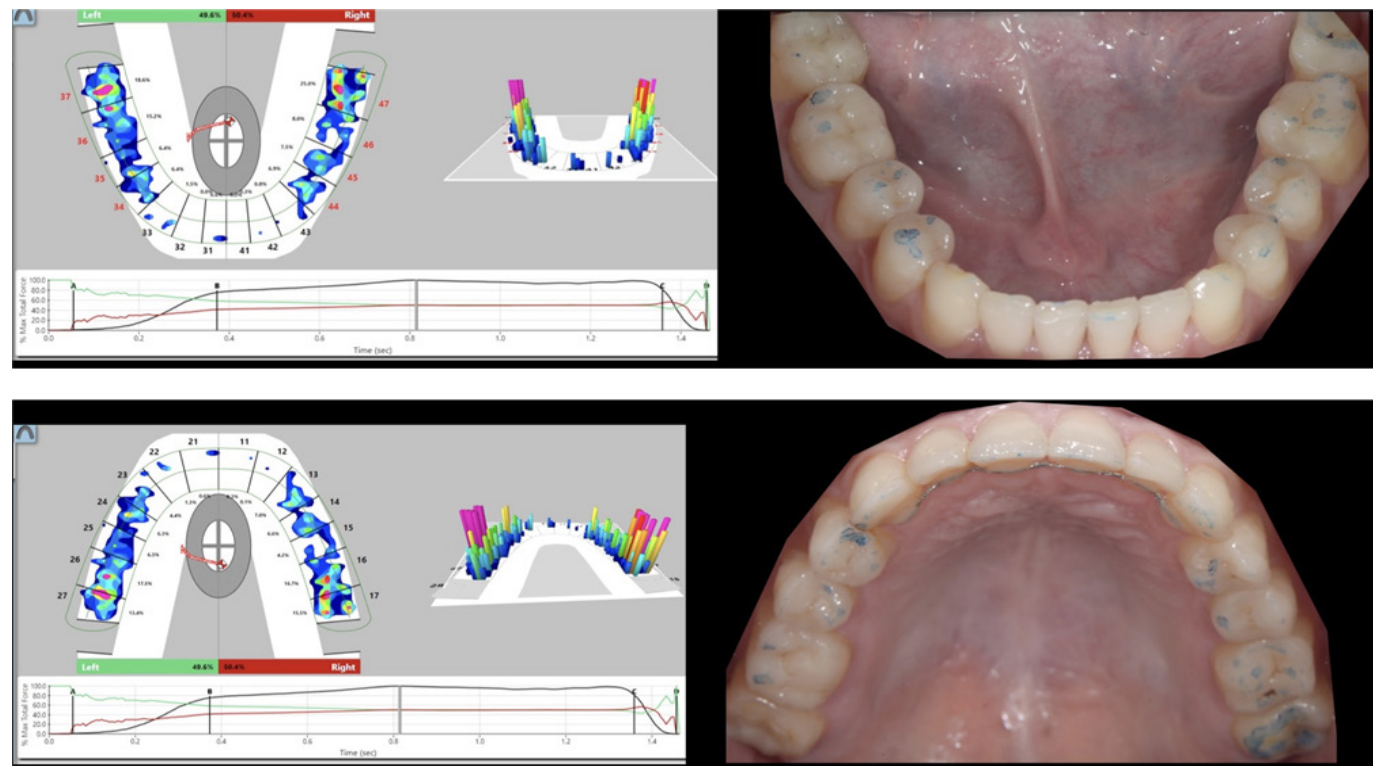

Figure 3. T-Scan analysis compared to clinical analysis. 
Analysis using articulating paper did not reveal any alteration in occlusal contact point distribution on the restored teeth, but a slightly increased intensity on the last antagonist molars was noted (Figure 3).

Upon intraoral scanner occlusal analysis, similar contact distribution was found between CR and MI (Figure 4).

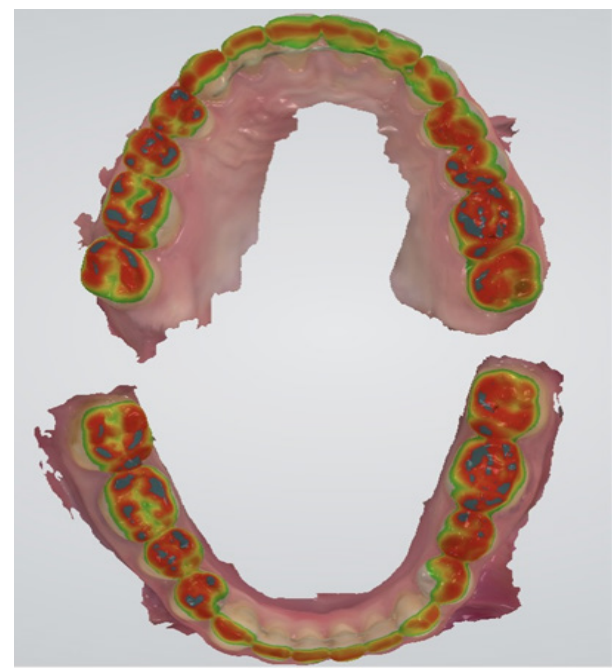

Figure 4. Occlusal analysis with Trios 3.

Instead, when T-Scan analysis was used, a similarity with the clinical registration was observed only during the final stages of the MI position. A difference appeared in contact point chronology, the first contact (being thus defined as premature) appearing between 2.7 and 3.7. Also, upon eccentric movement analysis in right laterotrusion, an active interference was spotted between the same pair of teeth that did not appear when articulating paper was used (Figure 5).

The selective polishing, indicated by the T-Scan device, led to the disappearance of sensitivity to cold.

\section{Case 2}

A female patient, aged 56, came to our clinic for functional and aesthetic restoration of both arches. Upon clinical and radiological examination, all upper teeth were extracted because of periodontal disease (Figure 6).

Bilateral external sinus lift was performed and 6 maxillary implants were inserted, allowing an all-on-six type Zirconia/ceramic screwed restoration to be applied. The lower jaw maintained the teeth 4.5, 4.4, 4.3, 3.2, 3.3 and 3.4, on which a Zirconia/ceramic bridge was cemented. In the lateral areas, 2 implants were inserted bilaterally and were restored through unified cemented Zirconia/ceramic crowns. During the 2-year follow-up, a bone loss of approx. $3 \mathrm{~mm}$ around the 3.6-implant was observed. In the context of proper oral hygiene, the cause of the bone loss was suspected to be due to occlusal overload. Occlusal analysis with articulating paper demonstrated an optimal occlusal contact point distribution in both CR and MI, slightly more intense between $4.4,4.5$ with $1.3,1.4$. The contact point distribution was relatively identical with the one obtained through intraoral scanning (Figure 7).



Figure 5. Active interferences on T-Scan analysis. 

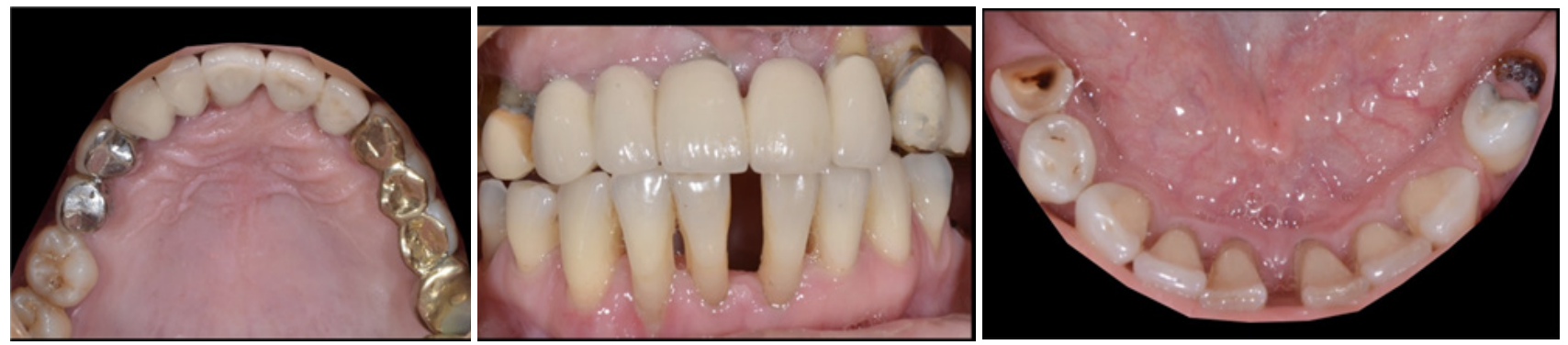

Figure 6. Initial situation.
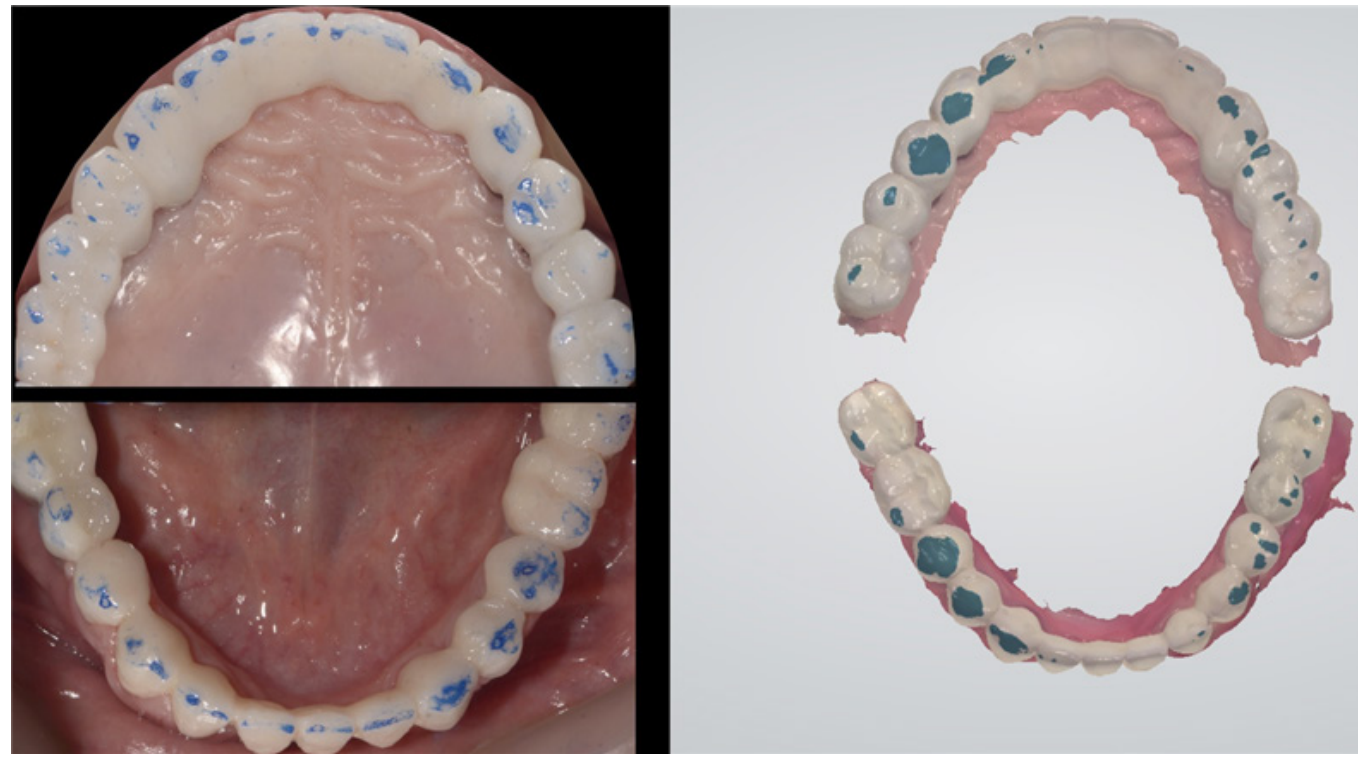

Figure 7. Clinical analysis with articulating paper and Occlusal analysis with Trios3.

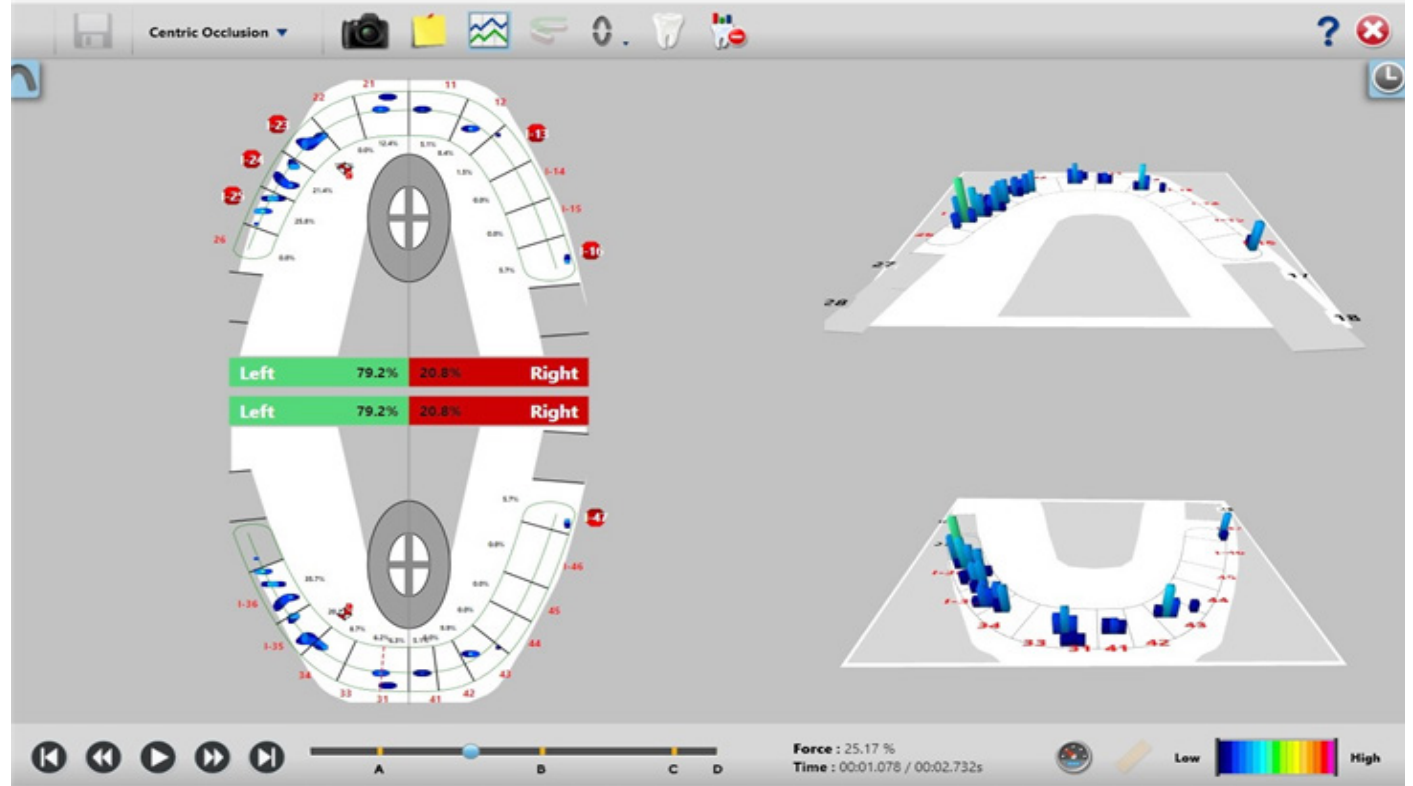

Figure 8. T-Scan analysis. 
Instead, T-Scan analysis with a timeline of contact point distribution identified the first contact with a heightened intensity on teeth 3.5 and 3.6. Also, an active interference in laterotrusion was noted on the pair 2.63.6. Both situations were not revealed by the articulating paper. Selective polishing was guided by the results of the T-Scan analysis (Figure 8).

\section{Case 3}

A female patient, aged 25, complained of articular pain (Figure 9).

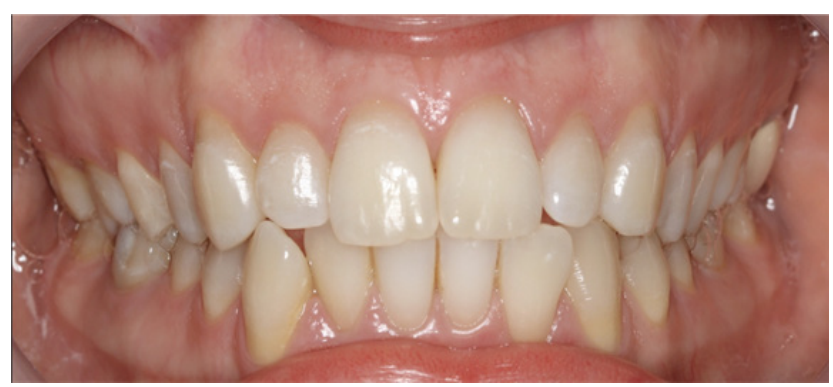

Figure 9. Initial situation.
The decision was made to begin temporomandibular disorder treatment by applying a rigid mandibular splint. Following articular pain remission and the repositioning of the mandible in $\mathrm{CR}$, bimaxillary orthodontic treatment was initiated in order to cure mandibular crowding, increase frontal overbite and, thus, obtain posterior disocclusion during mandibular eccentric movements. The treatment was completed prosthetically using inlays, overlays and lithiumdisilicate crowns on the lateral areas in order to stabilise the $\mathrm{CR} / \mathrm{MI}$ position and palatal veneers on teeth $1.3,2.1$ and 2.3 for re-establishment of the anterior and canine guidance (Figure 10).

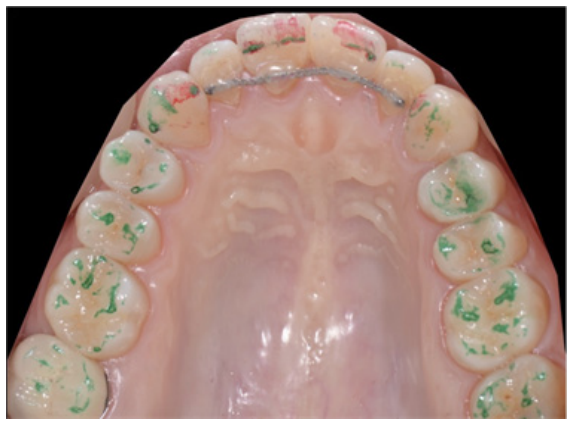

Figure 10. End result after orthodontic and prosthodontics treatment.

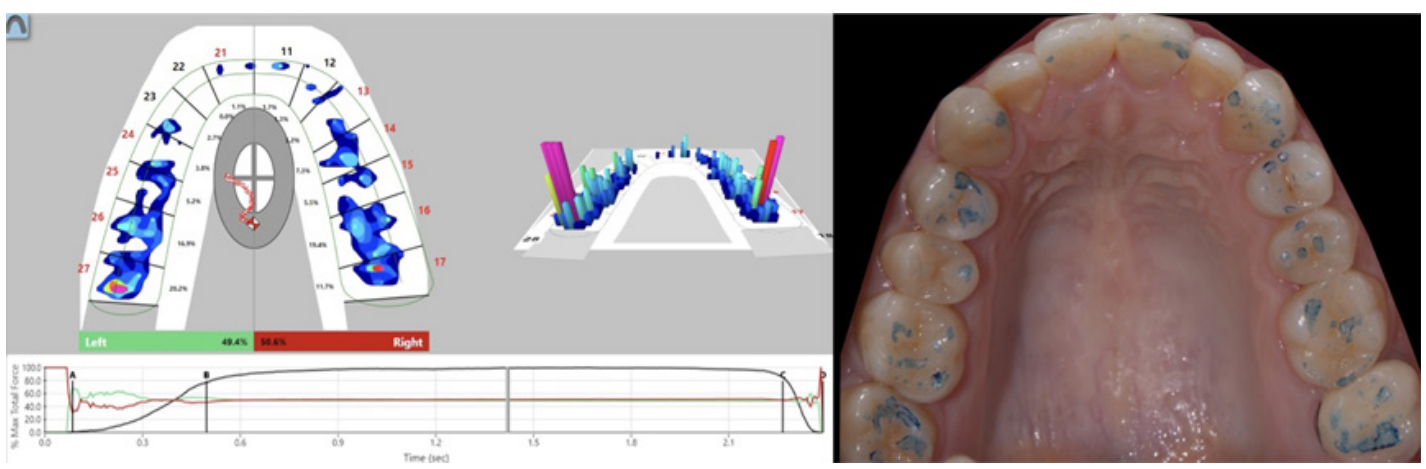

Figure 11. Articulating paper and T-Scan analysis in centric occlusion.

At the 2-year follow-up, the absence of any kind of symptoms was noted. At the same time, the data collected clinically, by intraoral scanner and by the T-Scan device was the identical, both in centric occlusion and in eccentric protrusive and laterotrusive movements. Additional information gathered by the T-Scan device refers to quantification of left-right forces, the intensities applied on the pairs of antagonist teeth and the exact moment of their occurrence (Figure 11, 12).

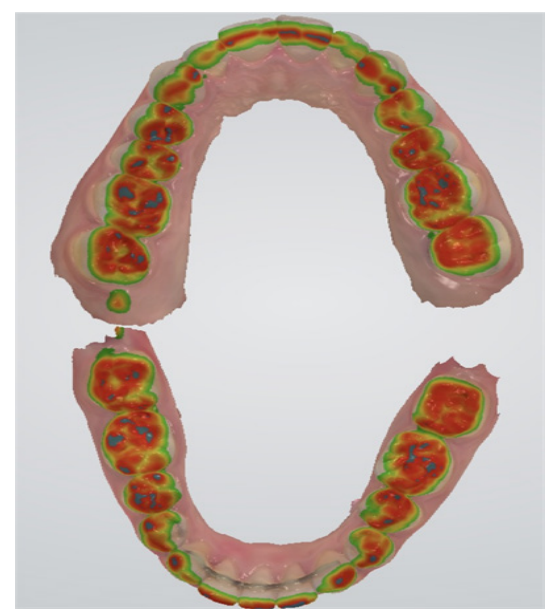

Figure 12. Trios 3 occlusal analysis. 


\section{Discussion}

Complying with functional occlusion criteria is one of the most important steps in maintaining stable results at the end of a treatment. Classical occlusal analysis involves applying articulating papers of different thicknesses and colours between the dental arches in order to detect the location and intensity of the contacts [14-18]. The intensity of the antagonist contact points is evaluated by the intensity of the colour marked on the teeth. Studies have demonstrated that there is no direct link between the area marked with the articulating paper and the force applied, even if there is a tendency of surface increase upon increase of the applied force $[19,20]$. Intraoral scanning offers the possibility to scan the occlusion and to visualize it after superimposing the scanned virtual models of the 2 arches. Accuracy of scanners is different regarding both fidelity and precision. Beside scanner value, errors may often appear because of the scanning technique and image superposition, which are operator-dependent. Also, errors may occur due to the way the patient performs occlusion when asked (during occlusion scanning on the left side ("Bite 1") and on the right side ("Bite 2")), which may lead to incorrect superpositions. Another limitation of intraoral scanners stems from the impossibility to measure the intensity of the occlusal forces [21].

Computerized T-Scan analysis helps by providing a more thorough occlusal analysis, which offers information regarding occlusion evolution on a digital timeline, contact chronology, intensity, and balance (or lack of) between the left and the right side at every moment of registration [22-24]. Among the disadvantages, there is the operatordependent factor (to some extent) and the fact that the sensor is not always appropriate for all arch shapes. The sensor may create discomfort when placed intraorally, thus, it may induce an alteration of the mandibular movements. Therefore, it is advisable to have repetitive recordings for safety reasons $[25,26]$.

\section{Conclusions}

Classical occlusal analysis, even if it has wide clinical applicability, does not offer all the pieces of information required for a successful occlusal balancing. Intraoral scanners may provide similar information to the clinical examinations, but the discrepancies between them raises the question which is best to be used as a reference during treatment. Computerized T-Scan analysis may bring additional extremely valuable information regarding force intensity, the moment of occurrence and a much more precise localization.

Clinical data relevant to this study were collected anonymously, without allowing patient identification. These data were included in the present study in the form of anonymous codes that do not refer to personal identification data. From an ethical point of view, this project will be subject to all the norms and National and European laws in force, of the European Rule of personal data protection no $679 / 2016$ and will observe the norms in force related to the protection of personal data and human rights.

\section{References}

1. Steinmassl PA, Klaunzer F, Steinmassl O, Dumfahrt H, Grunert I. Evaluation of Currently Avaiable CAD/CAM Denture Systems. Int J Prosthodont. 2017;30:116-122.

2. Wesemann C, Muallah J, Mah J, Bumann A. Accuracy and efficiency of full-arch digitalization and 3D printing: A comparison between desktop model scanners, an intraoral scanner, a CBCT model scan, and stereolithographic 3D printing. Quintessence Int. 2017;48:41-50.

3. Nedelcu R, Olsson P, Nyström I, Rydén J, Thor A. Accuracy and precision of 3 intraoral scanners and accuracy of conventional impressions: A novel in vivo analysis method. J Dent. 2018;69:110-118.

4. Rutkūnas V, Dirsè J, Bilius V. Accuracy of an intraoral digital scanner in tooth color determination. J Prosthet Dent. 2019 Jun 18. (19)30074-5. doi: 10.1016/j.prosdent.2018.12.020. [Epub ahead of print]

5. Latham J, Ludlow M, Mennito A, Kelly A, Evans Z, Renne W. Effect of scan pattern on complete-arch scans with 4 digital scanners. J Prosthet Dent. 2019 Apr 11. 13(19)301520. doi: 10.1016/j.prosdent.2019.02.008. [Epub ahead of print]

6. Di Fiore A, Meneghello R, Graiff L, Savio G, Vigolo $\mathrm{P}$, Monaco $\mathrm{C}$, et al. Full arch digital scanning systems performances for implant-supported fixed dental prostheses: a comparative study of 8 intraoral scanners. J Prosthodont Res. doi:10.1016/j.jpor.2019.04.002

7. Maestre-Ferrín L, Romero-Millán J, Peñarrocha-Oltra D, Peñarrocha-Diago M. Virtual articulator for the analysis of dental occlusion: an update. Med Oral Patol Oral Cir Bucal. 2012;17:e160-e163.

8. Delong R, Ko CC, Anderson GC, Hodges JS, Douglas WH. Comparing maximum intercuspal contacts of virtual dental patients and mounted dental casts. J Prosthet Dent. 2002;88:622-630.

9. Dees A, Kess K, Proff P, Schneider S. The use of the T-Scan system in occlusal diagnosis. Dtsch Zahn Mund Kieferheilkd Zentralbl. 1992;80:145-151.

10. Franklin P, McLelland R, Brunton P. An investigation of the ability of computerized axiography to reproduce occlusal contacts. Eur J Prosthodont Restor Dent. 2010;18:17-22.

11. Tamaki K, Cělar AG, Beyrer S, Aoki H. Reproduction of excursive tooth contact in an articulator with computerized axiography data. J Prosthet Dent. 1997;78:373-378.

12. Bozhkova TP. The T-SCAN System in Evaluating Occlusal Contacts. Folia Med (Plovdiv). 2016;58:122-130. doi:10.1515/folmed-2016-0015

13. Garrido Garcia VC, Garcia Cartagena A, González Sequeros O. Evaluation of occlusal contacts in maximum intercuspation using the T-Scan system. J Oral Rehabil. 1997;24:899-903. 
14. Afrashtehfar K, Qadeer S. Computerized occlusal analysis as an alternative occlusal indicator. Cranio. 2016;34:52-57.

15. Okeson J. Management of temporomandibular disorders and occlusion. St. Louis: Mosby Elsevier; 2013: pp. 21-475.

16. Dawson PE. Functional occlusion. St. Louis: Mosby Elsevier; 2007: pp. 3-600.

17. Buduru S. Analiza ocluziei dentare - clinic versus articulator [Analysis of dental occlusion - clinical versus articulatory]. Cluj-Napoca: Editura Napoca Star; 2018: pp. 20-84.

18. Dos Santos J. Occlusion Principles and Treatment. Chicago: Quintessence Pub. Co.; 2007: pp. 22-238.

19. Qadeer S, Kerstein R, Kim RJ, Huh JB, Shin SW. Relationship between articulation paper mark size and percentage of force measured with computerized occlusal analysis. J Adv Prosthodont. 2012;4:7-12.

20. Cerna M, Ferreira R, Zaror C, Navarro P, Sandoval P. Validity and reliability of the T-Scan(®) III for measuring force under laboratory conditions. J Oral Rehabil. 2015;42:544-551.
21. Ayuso-Montero R, Mariano-Hernandez Y, Khoury-Ribas L, Rovira-Lastra B, Willaert E, Martinez-Gomis J. Reliability and Validity of T-scan and 3D Intraoral Scanning for Measuring the Occlusal Contact Area. J Prosthodont. 2019 Jul 3. doi: 10.1111/jopr.13096. [Epub ahead of print]

22. Kerstein RB. Current applications of computerized occlusal analysis in dental medicine. Gen Dent. 2001;49:521-530.

23. Kerstein RB. T-scan III applications in mixed arch and complete arch, implant -supported prosthodontics. Dent Implantol Update. 2008;19:49-53.

24. Garg AK. Analyzing dental occlusion for implants: Tekscan's TScan III. Dent Implantol Update. 2007;18:65-70.

25. Yamamura M, Takahashi A, Aoki H, Takeuchi N, Endo Y, Tamaki K, et al. A study on display and accuracy of occlusal contacts by means of T-Scan System. Kanagawa Shigaku. 1990;25:236-241.

26. Garcia Cartagena A, Gonzalez Sequeros O, Garrido Garcia VC. Analysis of two methods for occlusal contact registration with the T-Scan system. J Oral Rehabil. 1997;24:426-432. 